\title{
The Validity and Reliability Study of Turkish Version of the Strengths Use Questionnaire
}

\author{
Ahmet AKIN ${ }^{1}$, Umran AKIN ${ }^{2}$ and Res. Assist. Fatma INCEMAN ${ }^{3}$ \\ ${ }^{1,2}$ Sakarya University Faculty of Education Department of Educational Sciences \\ ${ }^{3}$ Amasya University Faculty of Education Department of Educational Sciences
}

\begin{abstract}
The present study investigated the validity and reliability of Turkish version of Strengths Use Questionnaire (Wood, Linley, Maltby, Kashdan, \& Hurling, 2011). The sample of study consists of 244 university students. Of the participants 166 were female and 78 were male and the mean age of them was 20,4. In this study construct validity and internal consistency reliabilities of the scale were examined. The results of confirmatory factor analysis indicated that the model was well fit $\left(x^{2}=204.70, d f=74, R M S E A=.085, N F I=.93\right.$, $C F I=.94$, IFI=.94, and SRMR=.046). Cronbach alpha internal consistency reliability coefficient of the scale was .94. Overall findings demonstrated that this scale had acceptable and fairly high validity and reliability scores.
\end{abstract}

Keywords: Strengths Use, Confirmatory Factor Analysis, Validity, Reliability

\section{Introduction}

Personal strengths are the personal properties of an individual that allow him/her to perform well. The broader positive psychological prediction that using people strongest characteristics leads to increased wellbeing (Wood et al., 2011). In this case appears to be strong need to have a reliable and valid measurement tool to measure Turkish individual's levels of strengths use. Thus the aim of this research is to translate the Strengths Use Questionnaire (Wood et al., 2011) to Turkish and to examine its psychometric properties. This questionnaire contains 14 items (e.g., "I am regularly able to do what I do best.") with each item rated on a 7-point Likert-type scale. The Strengths Use Questionnaire was found to have an internal consistency reliability coefficient of .97.

\section{Method}

The study was conducted on 244 university students from different programs of Education Faculty of Amasya University, Turkey. Of the participants 166 were female and 78 were male and the mean age of them was 20,4. Primarily the Strengths Use Questionnaire was translated into Turkish by three academicians. After that the Turkish form was back-translated into English and examined the consistency between the Turkish and English forms. Than Turkish form has been reviewed by two academicians from educational sciences department. Finally they discussed the Turkish form and along with some corrections this scale was prepared for validity and reliability analyses. In this study confirmatory factor analysis (CFA) was executed to confirm the original scale's structure in Turkish culture. As reliability analysis internal consistency coefficient and the itemtotal correlations were examined.

\section{Results}

Validity. The results of confirmatory factor analysis indicated that the model was well fit $\left(x^{2}=204.70, d f=74\right.$, RMSEA=.085, NFI=.93, CFI=.94, IFI=.94, and SRMR=.046). According to these values it can be said that the structural model of Strengths Use Questionnaire which consists of one factor was well fit to the Turkish culture (Marsh, Balla, \& McDonald, 1988). 


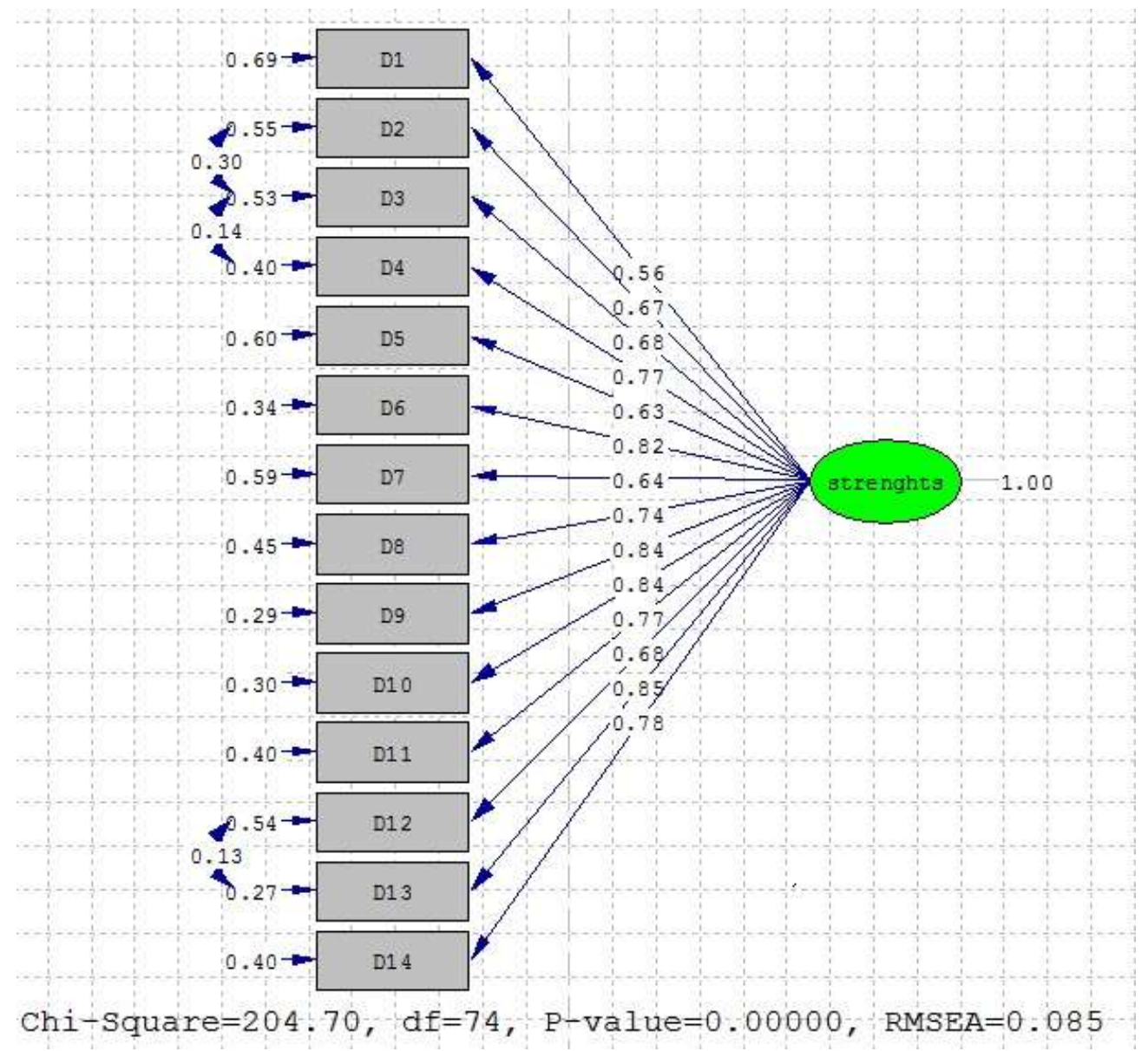

Fig. 1: Results of confirmatory factor analysis of Strengths Use Questionnaire.

Reliability. Cronbach alpha internal consistency reliability coefficient of the scale was .94. The corrected item-total correlations of Strengths Use Questionnaire ranged from .56 to .84.

TABLE I: Corrected item-total correlations of Strengths Use Questionnaire

\begin{tabular}{ccccc}
\hline \hline Item no & $\begin{array}{c}\text { Scale Mean if } \\
\text { Item Deleted }\end{array}$ & $\begin{array}{c}\text { Scale Variance if } \\
\text { Item Deleted }\end{array}$ & $\begin{array}{c}\text { Corrected Item- } \\
\text { Total Correlation }\end{array}$ & $\begin{array}{c}\text { Cronbach's Alpha } \\
\text { iftem Deleted }\end{array}$ \\
\hline 1 & 66,5164 & 183,576 &, 560 &, 943 \\
2 & 66,5123 & 181,576 &, 694 &, 940 \\
3 & 66,5656 & 180,329 &, 706 &, 940 \\
4 & 66,9918 & 176,288 &, 760 &, 938 \\
5 & 67,8893 & 179,054 &, 622 &, 942 \\
6 & 67,0779 & 173,282 &, 797 &, 937 \\
7 & 67,6107 & 177,111 &, 613 &, 943 \\
8 & 67,4098 & 176,037 &, 710 &, 939 \\
9 & 67,2090 & 171,985 &, 796 &, 937 \\
10 & 67,2090 & 173,787 &, 792 &, 937 \\
11 & 67,0246 & 176,831 &, 744 &, 939 \\
12 & 67,3115 & 175,466 &, 672 &, 941 \\
13 & 67,3770 & 170,162 &, 836 &, 936 \\
14 & 67,1311 & 176,345 &, 738 &, 939 \\
\hline \hline
\end{tabular}




\section{Discussion}

The purpose of purpose of this study was to translate Strengths Use Questionnaire into Turkish and to examine its psychometric properties. Overall findings demonstrated that this scale had acceptable and fairly high validity and reliability scores and that it may be used as an efficient instrument in order to assess levels of strengths use of individuals of. So it can be said that the Turkish version of Strengths Use Questionnaire is a reliable and valid measure of the constructs it was intended to assess (Büyüköztürk, 2004; Marsh, Balla, \& McDonald, 1988; Tezbaşaran, 1996). Nevertheless, further studies that will use Strengths Use Questionnaire are important for its measurement force.

\section{References}

[1] Büyüköztürk, Ş. (2004). Veri analizi el kitabı. Ankara: Pegem A Yayıncılık.

[2] Marsh, H. W., Balla, J. R., \& McDonald, R. P. (1988). Goodness-of-fit indexes in confirmatory factor analysis: The effect of sample size. Psychological Bulletin, 103, 391-410.

http://dx.doi.org/10.1037/0033-2909.103.3.391

[3] Tezbaşaran. A. A. (1996). Likert tipi ölçek geliştirme kılavuzu. Ankara: Türk Psikologlar Derneği Yayınları.

[4] Wood, A. M., Linley, A., Maltby, J., Kashdan, T. B., \& Hurling, R. (2011). Using personal and psychological strengths leads to increases in well-being over time: A longitudinal study and the development of the Strengths Use Questionnaire. Personality and Individual Differences, 50, 15-19.

http://dx.doi.org/10.1016/j.paid.2010.08.004 